$\mathbb{T}$ periodica polytechnica

\author{
Transportation Engineering \\ $38 / 1(2010) 25+28$ \\ doi: 10.3311/pp.tr.2010-1.05 \\ web: http://www.pp.bme.hu/tr \\ (c) Periodica Polytechnica 2010
}

RESEARCH ARTICLE

\section{Possible methods of application of electronic freight and warehouse exchanges in solving the city logistics problems}

Gábor Kovács

Received 2009-09-03

\begin{abstract}
In general terms, electronic freight and warehouse exchanges are virtual market places established for the harmonization of freight demand and supply. Due to their characteristics, however, these may be also suitable for the division of capacities (capacity load and storage capacity) of certain freighters and forwarders. Upon these trade directed to cities may be optimized, as groupage transport may be organized to cities, or within these to districts, considering, at the same time, the possibility of acquiring back haul, as well. In addition to this, by the division, optimal exploitation of freight capacities trade directed to the cities may be significantly reduced with the application of a transfer location in the outskirts of the city and a related warehouse exchange.
\end{abstract}

\section{Keywords}

electronic freight exchange - electronic warehouse exchange . city logistics $\cdot$ route planning

\section{Gábor Kovács}

Department of Transportation Technology, BME, Bertalan L. u. 2.Building Z, Room 604, H-1111 Budapest, Hungary

e-mail: kovacsg@kku.bme.hu

\section{Introduction}

Several possible solutions are known for the problems of urban transport of goods in domestic and international technical literature. The reduction of empty run proportion of vehicles performing the supply of cities, the increase of vehicle utilization and the reduction of the numbers of runs are touched upon in several cases. For the examination of this a simulation model [1] was established, according to which the obtainable profit appears mainly in the reduction of empty runs. The before mentioned monograph expressly highlights the necessity of the establishment of a surface for electronic communication. The effects of such electronic surfaces on certain participants of freight market and on urban environment is examined in another monograph [2], which also points out its measurable significance, primarily through the development of cooperation between participants of freight market, the extension of clientele and the use of modern IT technologies. In addition to this, cooperation is touched upon in several monographs, and is a significant factor in the solution of problems [3].

A survey conducted on the possible future development of city logistics [4] mentions as important part field the application of communication sites. It considers as most important advantage the development of vehicle utilization (reduction of empty runs, organization of back haul), but also mentions that such electronic communication sites are perfectly suitable for organizing groupage transport, as well. For the co-ordination of demands and capacities an e-auction system may be suitable, as well, which, due to its characteristics is able to eliminate the negative effects of urban transport of goods [5].

As a matter of fact, electronic freight exchanges are the above mentioned virtual meeting surfaces, the objective of which is the synchronization of shippers and freighters (demand and supply) with the help of different electronic trading [6]. Freighters make their free vehicle capacity available, together with all of its important specifications, and considering these shippers may conduct capacity search. Similarly, by the same way shippers may also publish the main specifications regarding the transferable consignment. At the freight exchange, due to its characteristics, it is possible for freighters to use capacity excess and rent capac- 
ity surplus. The above mentioned principles may be applied for the use of storage service, where the demands of goods owners are matched with free storage capacities, and optionally also for the division of capacities.

The city logistics applications of electronic freight exchanges have presently become public knowledge only through straggling mentioning, detailed operation concept has not been elaborated. The first milestones of this are contained in the coming chapters, which primarily aim at proving the usefulness of electronic freight and warehouse exchanges.

\section{Possible models of application of electronic freight and warehouse exchanges in solving the city logistics problems}

\subsection{Goods supply system of the city supported with freight exchanges}

The basic task of electronic freight exchanges is to match freight capacity demands with transfer capacities. In the simplest case a shipper mandates the freighter to transfer a certain amount of goods (and through this in addition to certain vehicle utilization) from one place to another. At this time, however, two significant problems emerge: on one hand, the utilization of vehicles (carrying capacity, loading area, cubic capacity) may be low, and, on the other, the possibility of back haul is not certain, either. At this point the organizational function of electronic freight exchanges becomes significant, because there is possibility to find the freight task resulting in the optimal capacity utilization, or even the simultaneous transfer of the goods of more than one freighters (if the characteristics of the goods make this possible), and the possibility of organizing back haul is given, too. These characteristics make freight exchanges suitable for the development of efficiency of urban transport of goods, because with their help trade directed to the city may be performed with lower number of vehicles, by this causing less environmental harm.

The efficiency of freight exchanges may be understood easily through a factual example. An imaginary region may be seen in Fig. 1. of the 4 of its settlements one may be considered centre (No. 1), the others are middle-sized (No. 2 and No. 3) and small settlements (No. 4). The settlements are divided into further districts, in order to provide for the concentration of trade directed to one district.

Demands and capacities related to the cities may be matched upon their characteristic features (origin and destination, goods specifications, time of delivery), and similarly to the presently known and used route planning systems ,tours” may be modelled. Fig. 1 provides an example, where two routes were established (on the „map” indicated with dashed and double-dotted lines, the matrix on the left side describes the tour indicated with dashed line, the matrix on the right side describes the tour indicated with double-dotted line). In Tab. 1 basically a 'from where to where' matrix may be seen (by using the identifiers of cities and districts), the black squares indicate demands, while
,+" signs indicate whether the certain route serves the indicated demand.

In the case of the route indicated with dashed line possible methods of trade between a medium sized city (No. 3) and the centre are described, into this tour the fulfilment of the demands of a village on the route (No. 4) was included, as well. At the end of the tour the possibility of back haul is given, therefore the utilization of the vehicle is further increased. As it may be seen, the organization of such route - into which five different addresses and three different settlements are included - would be more difficult in the ordinary way and certainly would generate higher vehicle numbers. At the organization of routes in addition to the already considered aspects others, such as loading order shall be taken into account.

In the case of the tour indicated with the double-dotted line the indicated demands of all larger settlements in the district are fulfilled. The vehicle supplies the centre from city No. 2, and from here transports further goods to city No. 3. Therefore, due to the possibilities provided by freight exchanges (especially the simultaneous overview of a large number of demands) the supply of entire districts may be optimized (fewer vehicles arrive into the city with better utilization values; the order of visits may be optimized).

\subsection{City goods supply system supported by freight and warehouse exchanges}

A characteristic and also a slight disadvantage of the solution detailed in section 2.1 is that it is suitable for the organization of transfer of typically small quantity of goods, i.e. not of full load, because the procedure of matching more demands to one capacity makes sense only in this case. In reality many consignments filling the entire vehicle are transferred between cities and surrounding settlements. The known possible solution for such problem is the establishment of a transfer terminal in the outskirts of the city where from larger vehicles arriving to the outskirts of the city the goods are transferred to lower numbers of vehicles of larger capacity, which occasionally are more environment friendly.

Electronic warehouse exchanges provide supplementary solution to the above mentioned model, at which storage place may be booked - for temporary storage - for transferable goods. Considering Fig. 1 1 let us assume that at the borders of the centre one or more transfer terminals are established (or even one such establishment is placed at each main road), and the capacities of these may be booked. Freighters, therefore, may optimize their out of centre trade with the freight exchange, while when they arrive to the borders of the city they may place their goods to the storage place booked at the warehouse exchange. The goods will be further transferred to the districts of the city with larger capacity vehicles, which vehicles may be chosen at the freight exchange, as well (in other words: to the direction of the city services depart in daily fixed times, for example, the capacities of which may be booked through the freight exchange). Ware- 

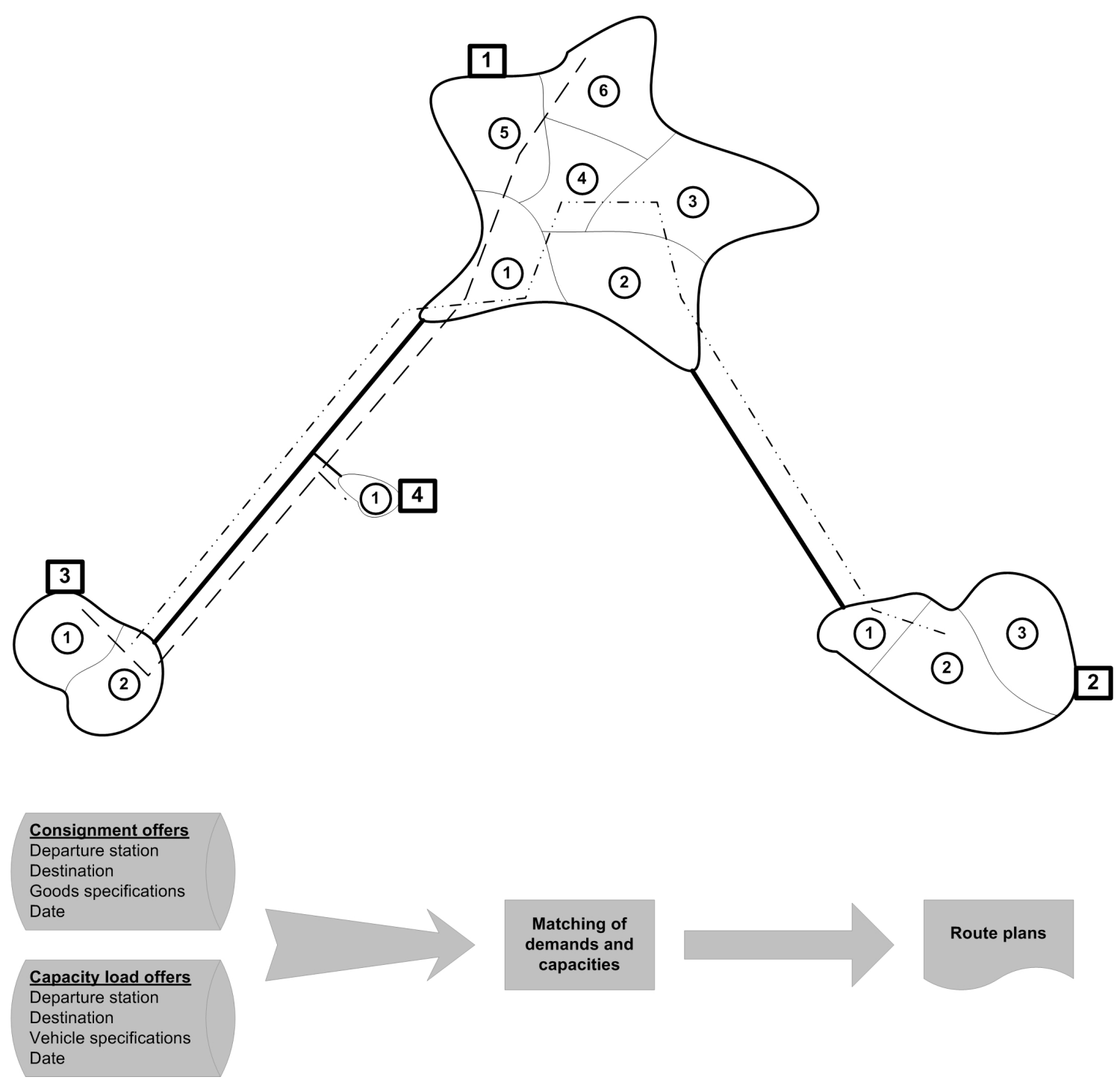

Date

Fig. 1. Role of freight exchanges in the increase of efficiency of urban goods supply

Tab. 1. Matching matrixes of demands and capacities

\begin{tabular}{|c|c|c|c|c|c|c|c|c|c|c|c|c|c|}
\hline \multicolumn{2}{|c|}{} & $\mathbf{1}$ & $\mathbf{2}$ & $\mathbf{3}$ & $\mathbf{4}$ & $\mathbf{5}$ & $\mathbf{6}$ & $\mathbf{1}$ & $\mathbf{2}$ & $\mathbf{3}$ & $\mathbf{1}$ & $\mathbf{2}$ & $\mathbf{1}$ \\
\hline \multirow{4}{*}{1} & 1 & & & & & & & & & & & & \\
\hline & 2 & & & & & & & & & & & & \\
\hline & 3 & & & & & & & & & & & & \\
\hline & 4 & & & & & & & & & & & & \\
\hline & 5 & & & & & & & & & & & & + \\
\hline & 6 & & & & & & & & & & & & \\
\hline \multirow{4}{*}{2} & 1 & & & & & & & & & & & & \\
\hline & 2 & & & & & & & & & & & & \\
\hline & 3 & & & & & & & & & & & & \\
\hline \multirow{3}{*}{3} & 1 & & & & & & + & & & & & & \\
\hline & 2 & & & & & + & & & & & & & \\
\hline 4 & 1 & + & & & & & & & & & & + & \\
\hline
\end{tabular}

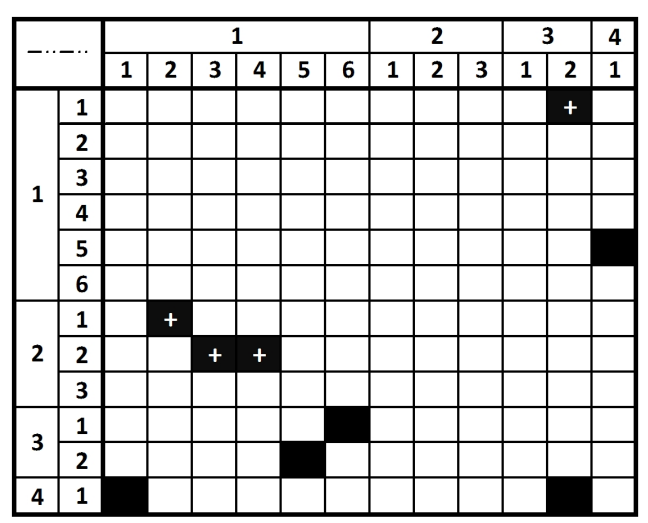

house exchange, therefore, has a supplementary role: it provides the possibility of choosing storage place established for the reduction of vehicle traffic arriving to the city to various directions.

\section{Conclusions}

The role fulfilled by freight exchanges in urban supply may be viewed as the company (e.g. wholesalers) applications of route planning systems: handling demands and capacities in one system the tours performed by vehicles are optimized. As a result of this these are suitable for the fulfilment of individual demands of smaller volume, not filling the entire load, because through the coordination of these they are able to establish collectingdistributing routes and to organize back haul, and through this to reduce the number of vehicles. In other words freight exchange, 
resulting from its characteristic, is one of the simplest, yet very efficient way of reducing vehicle traffic directed to cities.

Warehouse exchanges supplement freight exchanges and transfer terminals in the outskirts of the city, also by coordinating demands and capacities. In this case a transfer terminal in the outskirts of the city is necessary, therefore it is slightly more complex than the solution offered only by freight exchanges, but the trade of cities may be further reduced, as transport directed at inner districts are solved with large capacity vehicles or with other solutions known in the literature (e.g. by using the tram lines of the city). This is effective primarily if despite the effects of the freight exchange still large number of vehicles of low capacity utilization value arrive to the city (some possible reasons of this: freighters and shippers use freight exchange insufficiently, these vehicles are not allowed to enter the city, the leaders of the city aim at further improvements, etc.).

Finally a conclusion may be drawn according to which at the expense of relatively low investment with the proper motivation of shippers and freighters (all capacities and demands shall be included into the electronic system) an electronic freight and warehouse exchange could be easily established, with the help of which the taint of city roads could be reduced. In itself, however, it is not a sufficient solution, because the introduction of further city logistics systems known from literature, available in a relatively large number the ones best suitable to the Hungarian conditions shall be also necessary.

\section{References}

1 Holguín-Veras $\mathbf{J}$, On the estimation of the maximum efficiency of the trucking industry: Implications for city logistics, Logistics systems for sustainable cities proceedings of the 3rd International conference on city logistics (Madeira, Portugal), 25 June, 2003, pp. 123-134.

2 van Duin J H R, Kneyber J C, Towards a matching system for the auction of transport orders, Logistics systems for sustainable cities proceedings of the 3rd International conference on city logistics (Madeira, Portugal, 25 June, 2003), pp. 163-177.

3 Hayashi $\mathbf{K}$, Ono $\mathbf{H}$, Yano $\mathbf{Y}$, Efforts to make distribution and transportation more efficient through cooperation among Japanese companies, Recent advances in city logistics proceedings of the 4th International conference on city logistics (Langkwai, Malaysia), 12 July, 2005, pp. 347-360.

4 Hayashi K, Yano Y, Future city logistics in Japan from the shippers' and carriers' view - prospects and recent measures to develop them, Logistics systems for sustainable cities proceedings of the 3rd International conference on city logistics (Madeira, Portugal, 25 June, 2003), pp. 263-277.

5 Jonkman P, Taniguchi E, Yamada T, Evaluation of a freight auction in an urban transport network, Recent advances in city logistics proceedings of the 4th International conference on city logistics (Langkwai, Malaysia), 12 July, 2005, pp. 207-220.

6 Kovács G, Elektronikus fuvar- és raktárbörzék, mint korszerü logisztikai eszközök, Logisztikai Évkönyv 2007-2008, pp. 211-215. Electronic freight and warehouse exchanges as instruments of modern logistics. 